This article was downloaded by: [Lu, Zhong]

On: 30 July 2010

Access details: Access Details: [subscription number 924882512]

Publisher Taylor \& Francis

Informa Ltd Registered in England and Wales Registered Number: 1072954 Registered office: Mortimer House, 3741 Mortimer Street, London W1T 3JH, UK

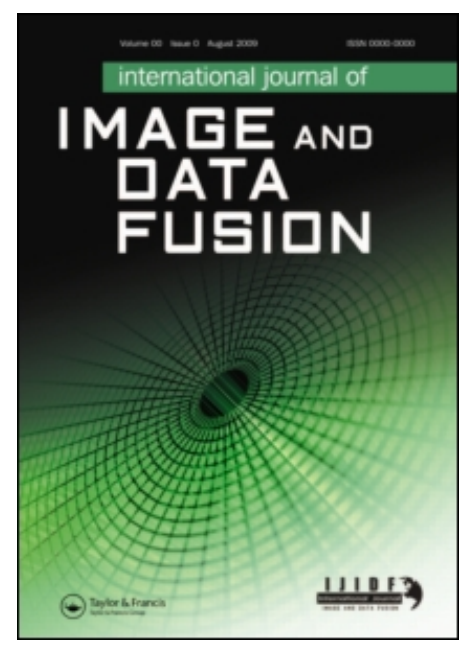

\title{
International Journal of Image and Data Fusion
}

Publication details, including instructions for authors and subscription information:

http://www.informaworld.com/smpp/title $\sim$ content=t911470591

\section{Radar image and data fusion for natural hazards characterisation}

Zhong Lü; Daniel Dzurisina; Hyung-Sup Jungb; Jixian Zhang; ; Yonghong Zhang

${ }^{a}$ US Geological Survey (USGS), Vancouver, WA 98683, USA ${ }^{\mathrm{b}}$ The University of Seoul, Seoul 130-743,

Korea ${ }^{\mathrm{c}}$ Chinese Academy of Surveying and Mapping, 28 Lianhuachixi Road, Haidian District, Beijing 100830, P.R. China

Online publication date: 29 July 2010

To cite this Article Lu, Zhong, Dzurisin, Daniel , Jung, Hyung-Sup, Zhang, Jixian and Zhang, Yonghong(2010) 'Radar image and data fusion for natural hazards characterisation', International Journal of Image and Data Fusion, 1: 3, 217 242

To link to this Article: DOI: $10.1080 / 19479832.2010 .499219$

URL: http://dx.doi.org/10.1080/19479832.2010.499219

\section{PLEASE SCROLL DOWN FOR ARTICLE}

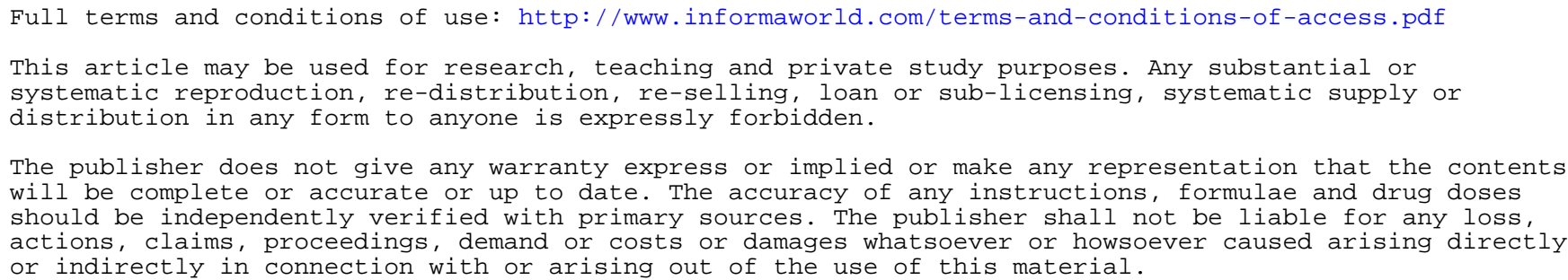




\title{
Radar image and data fusion for natural hazards characterisation
}

\author{
Zhong Lu ${ }^{\text {a* }}$, Daniel Dzurisin ${ }^{\mathrm{a}}$, Hyung-Sup Jung ${ }^{\mathrm{b}}$, \\ Jixian Zhang ${ }^{\mathrm{c}}$ and Yonghong Zhang ${ }^{\mathrm{c}}$ \\ ${ }^{a}$ US Geological Survey (USGS), Vancouver, WA 98683, USA; ${ }^{b}$ The University of Seoul, \\ Seoul 130-743, Korea; ' Chinese Academy of Surveying and Mapping, \\ 28 Lianhuachixi Road, Haidian District, Beijing 100830, P.R. China
}

(Received 12 September 2009; final version received 23 February 2010)

\begin{abstract}
Fusion of synthetic aperture radar (SAR) images through interferometric, polarimetric and tomographic processing provides an all-weather imaging capability to characterise and monitor various natural hazards. This article outlines interferometric synthetic aperture radar (InSAR) processing and products and their utility for natural hazards characterisation, provides an overview of the techniques and applications related to fusion of SAR/InSAR images with optical and other images and highlights the emerging SAR fusion technologies. In addition to providing precise land-surface digital elevation maps, SAR-derived imaging products can map millimetre-scale elevation changes driven by volcanic, seismic and hydrogeologic processes, by landslides and wildfires and other natural hazards. With products derived from the fusion of SAR and other images, scientists can monitor the progress of flooding, estimate water storage changes in wetlands for improved hydrological modelling predictions and assessments of future flood impacts and map vegetation structure on a global scale and monitor its changes due to such processes as fire, volcanic eruption and deforestation. With the availability of SAR images in near real-time from multiple satellites in the near future, the fusion of SAR images with other images and data is playing an increasingly important role in understanding and forecasting natural hazards.
\end{abstract}

Keywords: synthetic aperture radar; interferometric synthetic aperture radar; natural hazards; image fusion

\section{Introduction to SAR and InSAR}

A synthetic aperture radar (SAR) is an advanced radar system that utilises image processing techniques to synthesise a large virtual antenna, which provides much higher spatial resolution than what is practical using a real-aperture radar. A SAR system transmits electromagnetic waves at a wavelength that can range from a few millimetres to tens of centimetres. Because a SAR actively transmits and receives signals backscattered from the target area, and because radar wavelengths are mostly unaffected by weather clouds, a SAR can operate effectively during day and night under most weather conditions. Through SAR processing (e.g. Curlander and McDonough 1991), both the intensity and phase of the radar signal backscattered from each ground resolution element (typically metres to sub-metres in size) can be calculated and combined to form a complexvalued SAR image that represents the radar reflectivity of the ground surface.

*Corresponding author. Email: lu@usgs.gov 
The intensity (or strength) of the SAR image is determined primarily by the terrain slope, surface roughness and dielectric constant (an electric property of material that influences radar return strength). The phase value of the SAR image is determined primarily by the apparent distance between the radar antenna and the ground target. In its simplest form, a SAR intensity image can be regarded as a thematic layer containing information about specific surface characteristics. A time sequence of SAR images can be used to image and monitor dynamic Earth processes, including surface changes induced by natural and man-made hazards and activities.

Interferometric synthetic aperture radar (InSAR) involves the fusion of two or more SAR images of the same area to extract the landscape topography and patterns of surface change, including ground deformation. An interferogram can be produced by combining the phase components of two SAR co-registered images of the same area acquired from similar vantage points. An interferogram formed in this way depicts range changes between the radar and the ground resolution elements, and can be used to derive both the landscape topography and subtle changes in surface elevation if the SAR images are acquired at different times (e.g. Massonnet and Feigl 1998, Rosen et al. 2000, Lu et al. 2007a).

For InSAR purposes, the spatial separation between two SAR antennas, or between two vantage points of the same SAR antenna, is called the baseline. Two antennas can be displaced in the along-track direction to produce an along-track InSAR image if the two SAR images are acquired with a short time lag (Goldstein and Zebker 1987, Carande 1994, Romeiser and Thompson 2000, Rosen et al. 2000, Zhang et al. 2009). Along-track InSAR can be used to measure the velocity of targets moving towards or away from the radar to determine sea-ice drift, ocean currents, river flows and ocean wave parameters. Alongtrack InSAR applications in the past have been limited to technology demonstration in experimental studies from airborne SAR observations. Radar fusion and InSAR applications presented in this article refer to the most common baseline configuration across-track InSAR where the two antennas are displaced in the cross-track direction. For cross-track InSAR, the two antennas can be mounted on a single platform for simultaneous, single-pass InSAR observation. This is the usual implementation for airborne systems (e.g. Topographic SAR (TOPSAR), Zebker et al. 1992) and spaceborne systems (e.g. Shuttle Radar Topography Mission (SRTM), Farr et al. 2007) for generating high-resolution, precise digital elevation models (DEMs) over large regions. Alternatively, InSAR images can be formed by using a single antenna on an airborne or spaceborne platform in nearly identical repeating flight lines or orbits for repeat-pass InSAR (Gray and Farris-Manning 1993, Massonnet and Feigl 1998). In this case, even though successive observations of the target area are separated in time, the observations will be highly correlated if the backscattering properties of the surface have not changed in the interim. In this way, InSAR is capable of measuring ground-surface deformation with subcentimetre vertical precision for $X$-band and C-band sensors $(\lambda=2-8 \mathrm{~cm})$, or fewcentimetre precision for L-band sensors $(\lambda=15-30 \mathrm{~cm})$, in both cases at a spatial horizontal resolution of tens of metres over an image swath (width) of a few tens of kilometres up to $\sim 100 \mathrm{~km}$. This is the typical implementation for spaceborne sensors, including European Space Agency (ESA) European Remote-sensing Satellite 1 (ERS-1), Japan Aerospace Exploration Agency (JAXA) Japanese Earth Resources Satellite 1 (JERS-1), ESA European Remote-sensing Satellite 2 (ERS-2), Canadian Space Agency (CSA) Canadian Radar Satellite 1 (RADARSAT-1), ESA European Environmental Satellite (Envisat), JAXA Japanese Advanced Land Observing Satellite (ALOS), 
CSA RADARSAT-2, German Aerospace Agency (DLR) TerraSAR-X and Italian COnstellation of small Satellites for the Mediterranean basin Observation (COSMOSkyMed) satellites (Table 1). The required band (wavelength) to monitor different natural hazards varies among applications (Zebker et al. 2007). For geological and hydrological hazards related to earthquakes, volcanoes and landslides and floods, L-band is the best choice. For cryosphere and ocean hazards, C-band is the preferred one. Of course, fusion of SAR images from different bands will surely improve hazards characterisation and monitoring.

\section{Fusion of SAR/InSAR images}

\subsection{Basic InSAR products}

Because InSAR processing involves the combination of two or more SAR images, it is inherently a type of data fusion (Simone et al. 2002). Typical InSAR processing includes precise registration of an interferometric SAR image pair, common Doppler/bandwidth filter to improve InSAR coherence, interferogram generation, removal of curved Earth phase trend, adaptive filtering, phase unwrapping, precision estimation of interferometric baseline, generation of a surface deformation image (or a DEM map), estimation of interferometric correlation and rectification of interferometric products. Using a single pair of SAR images as input, a typical InSAR processing chain outputs two SAR intensity images, a deformation map or DEM and an interferometric correlation map.

\subsubsection{SAR intensity image}

SAR intensity images are sensitive to terrain slope, surface roughness and target dielectric constant. Surface roughness refers to the SAR wavelength-scale variation in the surface relief. Radar dielectric constant is an electric property of material that influences radar return strength and is controlled primarily by moisture content of the imaged surface. Natural hazards often induce changes in surface roughness and dielectric constant of Earth's surface. For example, a forest fire can change the surface roughness as well as the moisture state, which can be sensed by SAR intensity images. Therefore, SAR intensity images alone can be used to map hazards-related landscape changes, whether natural or manmade. In cloud-prone areas, all-weather SAR intensity imagery can be one of the most useful data sources available to track the course of hazardous events. As an example, Figure 1(a) and (b), respectively, show two SAR intensity images acquired before and during the February-May 1997 eruption at Okmok volcano, Alaska. A lava flow emplaced during the eruption is clearly delineated in the co-eruption image. No cloud-free optical satellite image from Landsat or other civilian satellites is available for the entire 3-month-long eruption. This example demonstrates the value of all-weather SAR images for monitoring hazardous events in cloud-prone areas.

\subsubsection{InSAR coherence image}

An InSAR coherence image is a cross-correlation product derived from two co-registered complex-valued (both intensity and phase components) SAR images (Zebker and Villasenor 1992, Lu and Freymueller 1998). It depicts changes in backscattering characteristics on the scale of radar wavelength. Loss of InSAR coherence is often referred to as decorrelation. Decorrelation can be caused by the combined effects of: (1) thermal 


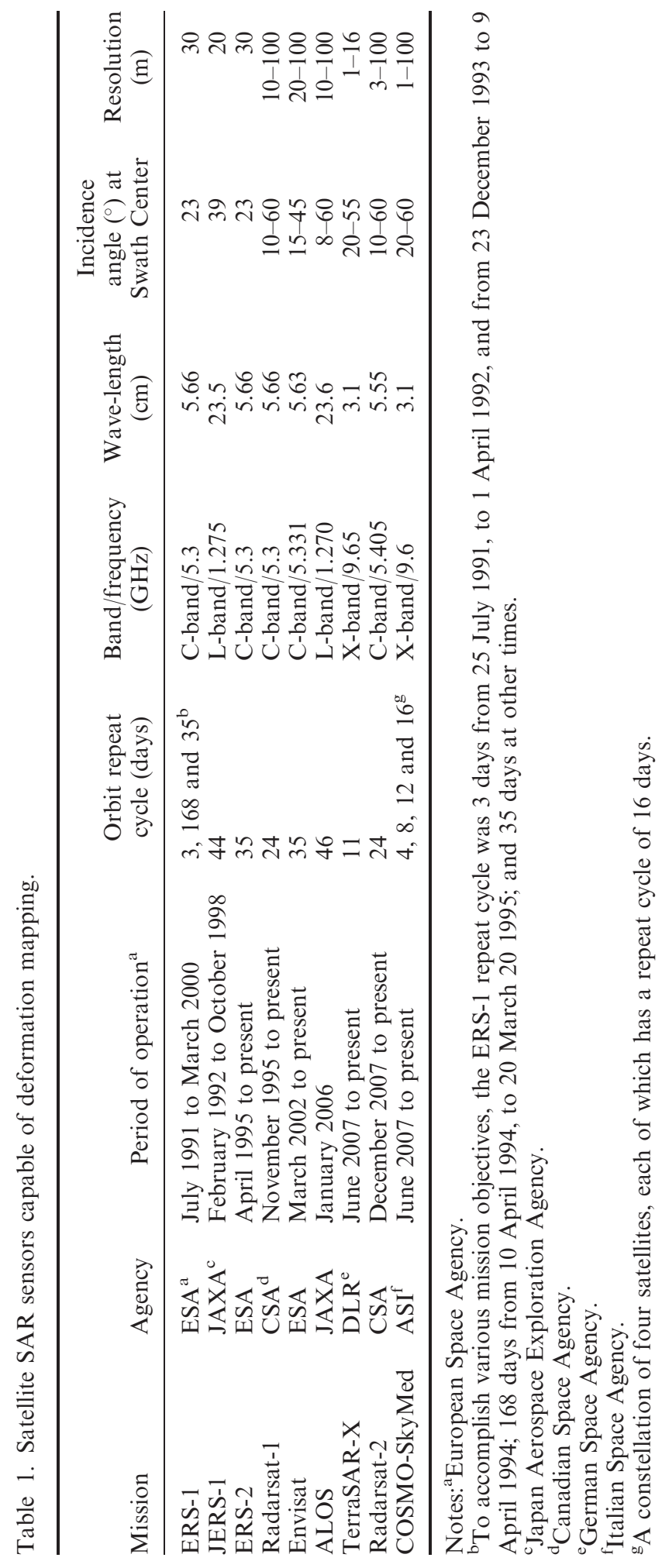



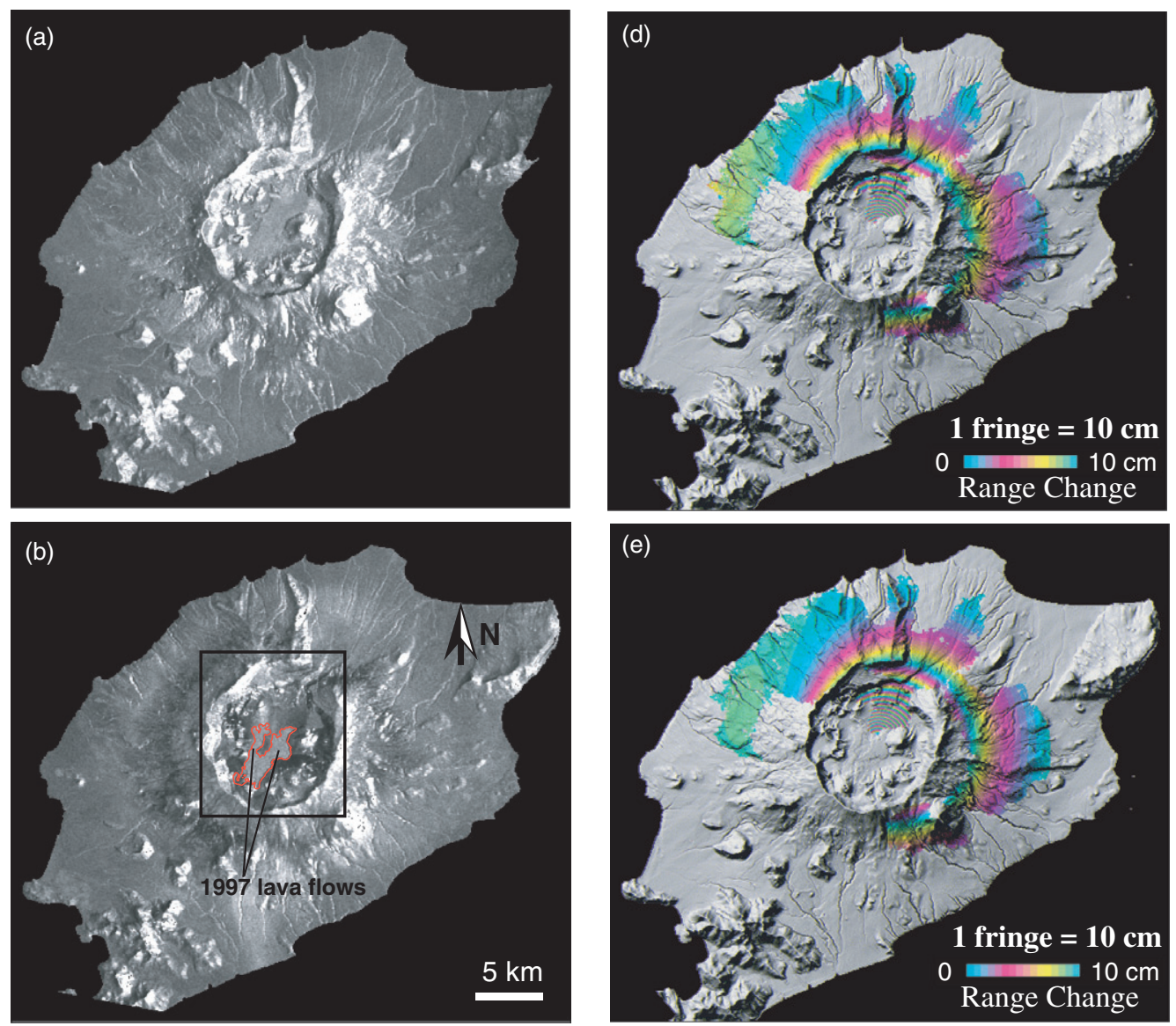

Figure 1. Examples of InSAR products derived through the fusion of multi-temporal SAR images for monitoring and characterising natural hazards. (a) ERS-1 SAR intensity image of Okmok volcano, Alaska, before its 1997 eruption. (b) JERS-1 SAR intensity image acquired during the 1997 Okmok eruption. The 1997 lava flows are outlined. Rectangle represents the extent of Figure 1(f). (c) Coherence map from SAR images acquired on 17 July and 25 September 1997. Loss of coherence (coloured in pink and purple) is primarily related to the emplacement of 1997 lava flow as well as changes due to ice/snow on the caldera rim, vegetation and erosion along coasts. (d) InSAR deformation image produced from two SAR images acquired before and after the 1997 eruption, showing volcano-wide deflation. Each fringe (full colour cycle) represents $10 \mathrm{~cm}$ of range change between the ground and satellite. Areas that lack interferometric coherence are uncoloured. (e) Synthetic InSAR image from a Mogi source that was derived from modelling the observed deformation in Figure 1(d). Each fringe (full colour cycle) represents $10 \mathrm{~cm}$ of range change between the ground and the satellite. Areas that lack interferometric coherence are uncoloured. (f) Thickness of lava flows emplaced inside Okmok Caldera during the 1997 eruption. Flow thickness was derived from the height difference between pre-eruption and post-eruption DEMs that were constructed from repeat-pass InSAR images. The extent of Figure 1(f) is outlined in Figure 1(b).

decorrelation caused by uncorrelated noise sources in radar instruments, (2) geometric decorrelation resulting from imaging a target from different look angles, (3) volume decorrelation caused by volume backscattering effects and (4) temporal decorrelation due to environmental changes over time (Zebker and Villasenor 1992, 

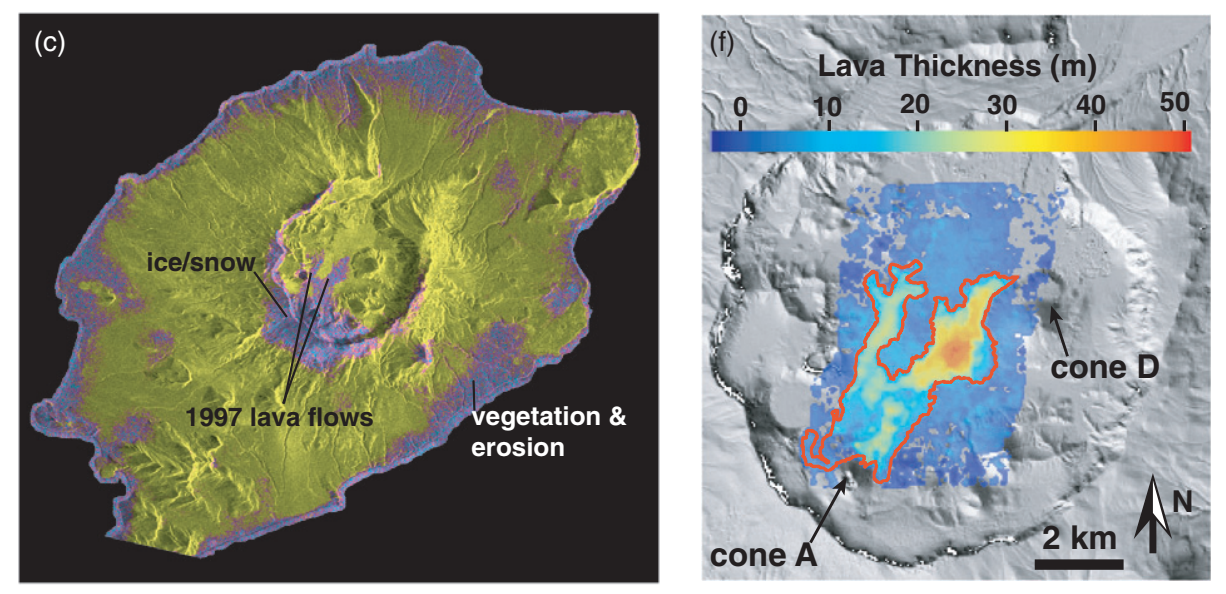

Figure 1. Continued.

$\mathrm{Lu}$ and Kwoun 2008). On the one hand, decorrelation renders an InSAR image useless for measuring ground surface deformation. Geometric and temporal decorrelation can be mitigated by choosing an image pair with short baseline and brief temporal separation, respectively. So choosing such a pair is recommended when the goal is to measure surface deformation, for example. On the other hand, the pattern of decorrelation within an image can indicate surface modifications caused by flooding, wildfire, volcanic eruption or earthquake shaking. In this way, time-sequential InSAR coherence maps can be used to map the extent and progression of hazardous events. For example, Figure 1(c) shows an InSAR coherence map for Okmok volcano that was derived from SAR images acquired on 17 July and 25 September 1997. Decorrelation (coloured in pink and purple) inside the summit caldera is due primarily to post-emplacement deformation of lava flows erupted there during the February-May 1997 eruption of Okmok. The decorrelation patterns outline extents of 1997 lava flows and snow and ice over the caldera rim, as well as vegetation and landscape erosion along coastal areas (Figure 1c; Lu et al. 2005).

\subsubsection{InSAR deformation image}

Unlike a SAR intensity image, an InSAR deformation image is derived from phase components of two overlapping SAR images. SAR is a side-looking sensor; so an InSAR deformation image depicts ground surface displacements in the SAR line-of-sight (LOS) direction, which include both vertical and horizontal motion. Typical look angles for satellite-borne SARs are less than $45^{\circ}$ from vertical; so LOS displacements in InSAR deformation images are more sensitive to vertical motion (uplift or subsidence) than horizontal motion. Here and henceforth, we conform to common usage by sometimes using the terms 'displacement' and 'deformation' interchangeably. Readers should keep in mind that, strictly speaking, displacement refers to a change in position (e.g. LOS displacement of a given resolution element or group of elements in an InSAR image), whereas deformation refers to differential motion among several elements or groups (i.e. strain). An InSAR deformation image produced from two SAR images that bracket the 
1997 Okmok eruption (Figure 1d) shows volcano-wide deflation of about $120 \mathrm{~cm}$ (Lu et al. 2005).

The spatial distribution of surface deformation data from InSAR images can be used to constrain numerical models of subsurface deformation sources, such as the spherical point pressure source (Mogi 1958), sill or dike source (Okada 1985), prolate spheroid source (Davis 1986; Yang et al. 1988) and penny-crack source (Fialko et al. 2001). By comparing the deformation patterns predicted by such idealised sources to the actual patterns observed with InSAR, scientists can identify a best-fitting source and estimate its location (horizontal coordinates and depth), shape, volume and pressure change. The bestfit point pressure source for the observed deformation interferogram in Figure 1(d) is located beneath the centre of Okmok Caldera at a depth of $3.0 \pm 0.5 \mathrm{~km}$ below sea level $(3.5 \pm 0.5 \mathrm{~km}$ below the Caldera floor), and the source volume change associated with the 1997 eruption is $-0.047 \pm 0.005 \mathrm{~km}^{3}$ ( $\mathrm{Lu}$ et al. 2005). Figure 1(e) shows the modelled interferogram based on the best-fit spherical point pressure source model. The model source fits the observed deformation pattern in Figure 1(d) quite well. Such a result can shed light on the processes responsible for observed surface deformation. In this case, the location of the model source $3.5 \pm 0.5 \mathrm{~km}$ below the centre of the Caldera floor is a compelling evidence that the deflation process is the withdrawal of magma from a storage zone beneath the volcano to feed the 1997 eruption. InSAR deformation images have an advantage for modelling purposes over point measurements made with a Global Positioning System (GPS), for example, because InSAR images provide more complete spatial coverage than what is possible with even a dense network of GPS stations. On the other hand, continuous GPS stations provide better precision and much better temporal resolution than what is possible with InSAR images, which is constrained by the orbital repeat times of SAR satellites. For hazards monitoring, a combination of periodic InSAR observations and continuous data streams from networks of in situ instruments is ideal.

\subsubsection{Digital elevation model}

A precise digital elevation model (DEM) can be a very important dataset for characterising and monitoring various natural hazards. As described earlier, the ideal SAR configuration for DEM production is a single-pass (simultaneous) two-antenna system (Madsen et al. 1993, Farr et al. 2007). However, repeat-pass single-antenna InSAR can also be used to produce useful DEMs (Ruffino et al. 1998, Sansosti et al. 1999). Either technique is advantageous in areas where the photogrammetric approach to DEM generation is hindered by persistent clouds or other factors ( $\mathrm{Lu}$ et al. 2003). There are many sources of error in DEM construction from repeat-pass SAR images, e.g. inaccurate determination of the InSAR baseline, atmospheric delay anomalies, possible surface deformation due to tectonic, volcanic or other sources during the time interval spanned by the images, etc. To generate a high-quality DEM, these errors must be identified and corrected using a multi-interferogram approach ( $\mathrm{Lu}$ et al. 2003). A data fusion technique such as the wavelet method can be used to combine DEMs from several interferograms with different spatial resolution, coherence and vertical accuracy to generate the final DEM product (Ferretti et al. 1999, Baek et al. 2005). One example of the utility of precise InSAR-derived DEMs is illustrated in Figure 1(f), which shows the extent and thickness of a lava flow extruded during 1997 Okmok eruption. The three-dimensional (3-D) distribution of the flow was derived by differencing two DEMs that represent the surface 
topography before and after the eruption. Multiple repeat-pass interferograms were used to correct various error sources and generate the high-quality DEMs ( $\mathrm{Lu}$ et al. 2003).

\subsection{Advanced SAR/InSAR fusion products}

\subsubsection{ScanSAR InSAR}

SARs onboard early spaceborne systems (ERS-1, ERS-2 and JERS-1) are of the stripmode type, in which radar-antenna pointing (i.e. the look angle) is fixed along the flight path and the antenna footprint covers a relatively narrow strip (swath) on the surface to one side of the orbit track ( $\sim 50-100 \mathrm{~km}$ wide in the cross-track direction). A strip-mode SAR can only acquire repeat-pass InSAR images at the frequency of its native sensor revisit period (35 days for ERS-1, ERS-2 and Envisat, 44 days for JERS-1, 24 days for RADARSAT-1 and RADARSAT-2, 46 days for ALOS and 11 days for TerraSAR-X). The new generation of SARs (Envisat, RADARSAT-1 and ALOS, and future systems) are capable of acquiring images in both strip-mode and scan-mode. A scan-mode SAR (ScanSAR) is achieved by periodically sweeping the antenna look angle to illuminate neighbouring sub-swaths in the cross-track direction, thereby increasing the size of the accessible image swath to $400-500 \mathrm{~km}$ (Figure 2). Because ScanSAR can acquire more

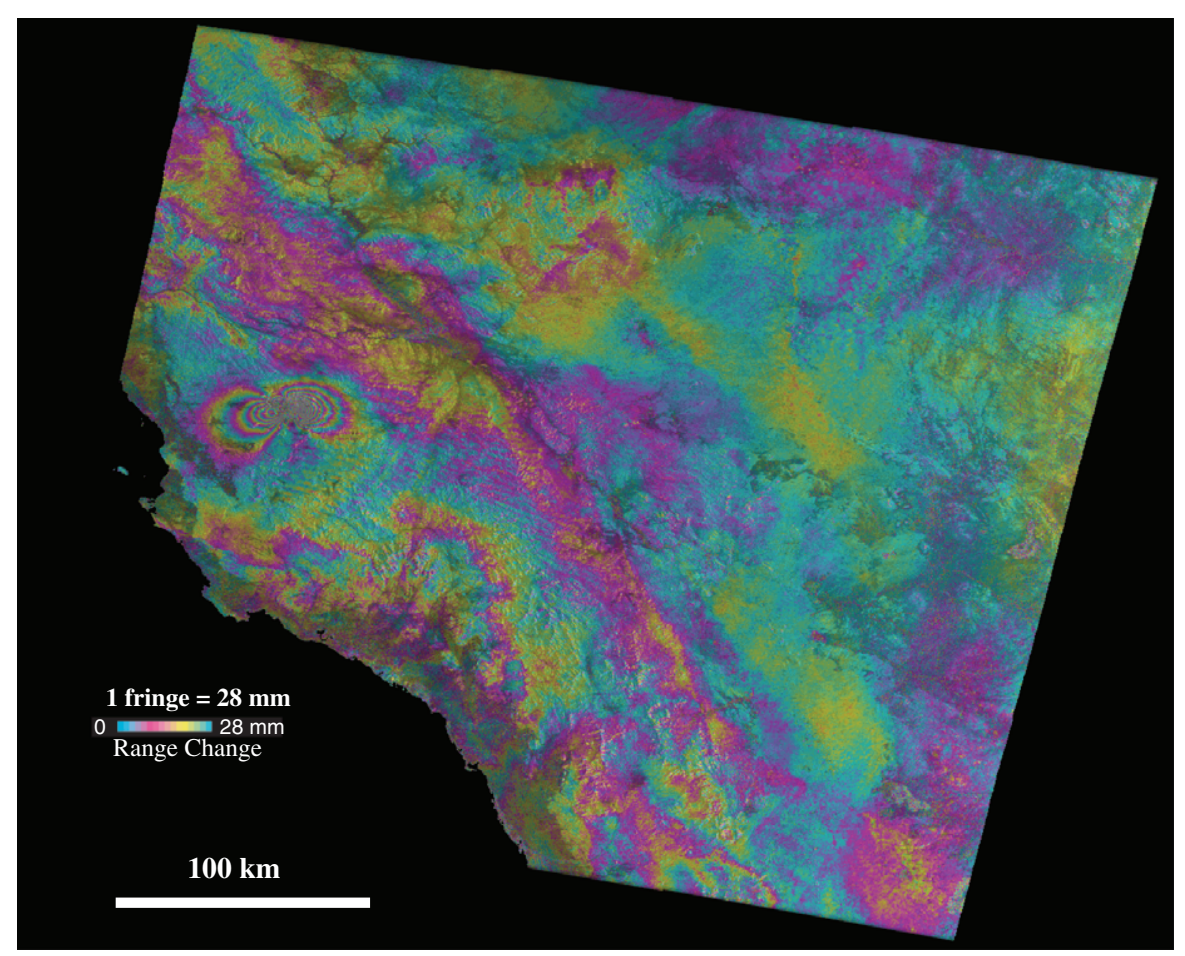

Figure 2. A ScanSAR InSAR image produced from ENVISAT ScanSAR images, showing ground surface deformation over an area of $\sim 400 \mathrm{~km}$ by $\sim 300 \mathrm{~km}$ in northwest Saudi Arabia near the Red Sea. Concentric fringes indicate ground surface uplift associated with magma intrusion that produced intensive earthquake swarms and ground cracks in May 2009. Please note that a typical strip-mode InSAR image only covers about $\sim 100 \mathrm{~km}$ wide swath, which is about $1 / 4$ of a ScanSAR InSAR image. 
frequent observations of a given study area than is possible with strip-mode SAR (albeit at somewhat lower spatial resolution), interferometric ScanSAR can significantly improve the temporal resolution of deformation mapping (Guarnieri and Rocca 1999, Holzner and Bamler 2002). For example, at $45^{\circ}$ latitude, Envisat can acquire four strip-mode images of a given target in 35 days: two on an ascending track, when the satellite travels approximately south to north, and two on a descending track (north to south). But during the same period, Envisat can acquire about 15 ScanSAR images of the same target. The four strip-mode images can be combined to produce one ascending-track interferogram and one descending-track interferogram, each spanning 35 days. For comparison, the images acquired in ScanSAR mode can be combined to produce a series of time-sequential interferograms; time separation between interferograms can be as little as 3 days. This makes ScanSAR InSAR a very attractive tool for monitoring transient deformation signals, including those commonly associated with volcanic unrest and post-seismic responses to major earthquakes.

\subsubsection{Multi-interferogram InSAR}

Multi-interferogram InSAR (Ferretti et al. 2001, 2007, Berardino et al. 2002, Hooper et al. 2007, Rocca 2007) is one of the most significant recent advances in InSAR image fusion to improve deformation measurement accuracy for improved hazards assessment and monitoring. 'Multi-' in this context refers to a series of InSAR observations in time, thus affording the opportunity to recognise spurious effects. The objective is to fuse multipleinterferogram measurements of the same area to characterise the spatial and temporal behaviours of the deformation signal and various artefacts and noise sources (atmospheric delay anomalies, orbit errors and DEM-induced artefacts), and then to remove the artefacts and anomalies to retrieve time-series deformation measurements at the SAR pixel level.

Among several approaches to multi-interferogram analysis, persistent scatterer InSAR (PSInSAR) is one of the newest and most promising data fusion techniques. PSInSAR uses the distinctive backscattering characteristics of certain ground targets (PS) and unique characteristics of atmospheric delay anomalies to improve the accuracy of conventional InSAR deformation measurements (Ferretti et al. 2001). The SAR backscattering signal of a PS target has a broadband spectrum in the frequency domain, implying that the radar phase of this kind of scatterer correlates over much longer time intervals and over much longer baselines than other scatterers. As a result, if the backscatter signal from a given pixel is dominated by return from one or more PS(s), the pixel remains coherent over long time intervals. Therefore, at PS pixels, the limitation imposed by loss of coherence in conventional InSAR analysis can be overcome. Because InSAR coherence is maintained at PS pixels, the atmospheric contribution to the backscattered signal, DEM error and orbit error can be identified and removed from the data using a multi-interferogram iterative approach. After these errors are removed, displacement histories at PS pixels can be resolved with millimetre accuracy (Figure 3; Lee et al. 2010). If a sufficient number of PS pixels exist in a series of interferograms, relative displacements among them can provide a relatively detailed picture of the surface deformation field.

\subsection{Applications of SAR/InSAR for natural hazards characterisation}

Through the fusion of two or more SAR images, InSAR products (intensity image, coherence image, deformation image and/or DEM image) can be generated to provide 

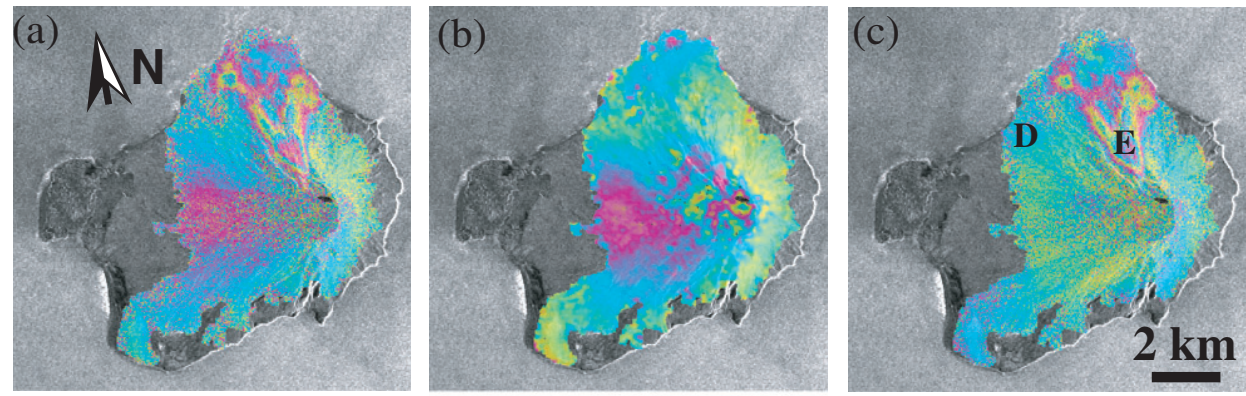

$-1.5 \mathrm{~cm}$

$1.5 \mathrm{~cm}$

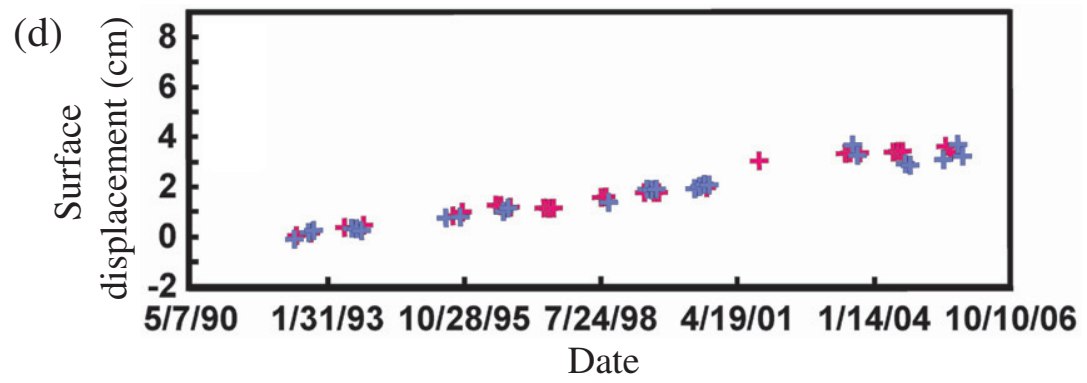

(e)

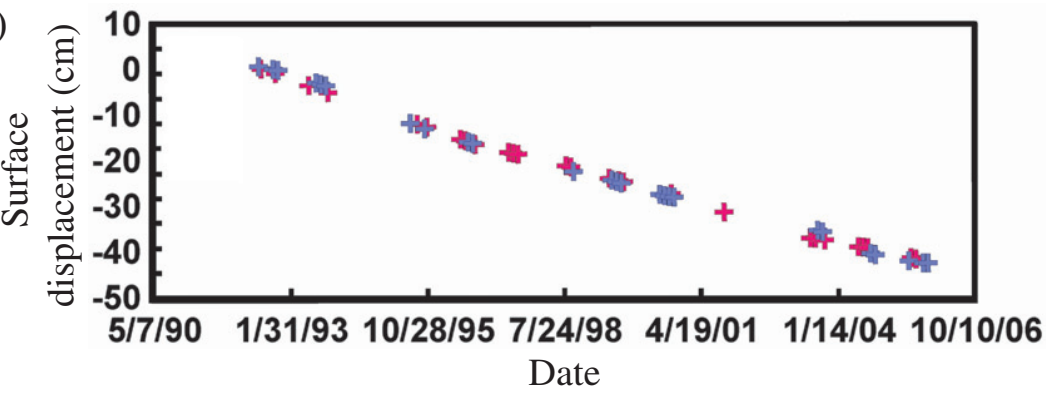

Figure 3. Example of fusing multi-temporal InSAR images to improve deformation mapping. (a) Observed interferogram of Augustine Volcano, Alaska, from SAR images acquired on 5 June 1992 and 30 July 1993. (b) Synthetic interferogram showing range changes due to atmospheric effects, which were modelled using spatial low-pass and temporal high-pass filtering during multiinterferogram InSAR processing. (c) Refined InSAR deformation image after multi-interferogram processing, which effectively removes artifacts due to baseline and atmospheric delay anomalies. (d) Line-of-sight (LOS) surface-displacement time-series at point $D$ (Figure 3c) on Augustine Volcano for the period 1992-2005. Red and purple symbols indicate time-series displacement histories at $D$ derived from multi-interferogram InSAR processing of SAR images from ERS-2 satellite tracks 229 and 501, respectively. (e) LOS surface-displacement time-series at point $E$ (Figure 3c) on Augustine Volcano for the period 1992-2005. Symbols and data processing as in Figure 3(d). Ground surface at location D inflated at a rate of $3 \mathrm{~mm} /$ year due presumably to magma intrusion while ground surface at $\mathrm{E}$ subsided at a rate of $3 \mathrm{~cm} /$ year due to thermal compaction of the pyroclastic flows from 1986 eruption (Lee et al. 2010).

timely information for characterising and monitoring natural hazards. These applications can be grouped into three categories: (1) mapping surface deformation caused by natural processes or human activities; (2) monitoring landscape changes by analysing SAR intensity and coherence images; and (3) mapping the extent and progression of hazardous 
events using time-sequential DEMs. Examples of each type of InSAR application are given in the following three sections. Obviously, the integration of various InSAR products with other remote sensing images will enhance the characterisation and monitoring of natural hazards (e.g. Singhroy 1995, Tralli et al. 2005).

\subsubsection{Hazards applications of InSAR deformation maps}

InSAR can map ground surface deformation at volcanoes both before and during eruptions, thereby providing useful information for the monitoring and assessment of hazards. InSAR maps of co-eruption deformation provide information about eruption dynamics, including the eruption rate as a function of time (e.g. Dzurisin 2003, 2007, Lu et al. 2007b). InSAR maps of inter-eruption deformation, the onset of which often precedes swarms of earthquakes and other eruption precursors, provide insights into the structure, magma plumbing system and the state of restless volcanoes (e.g. Lu 2007, Lu et al. 2002, 2007b).

InSAR also can be used to image ground surface displacements before, during and after large seismic events - information that is essential for hazard assessment and postdisaster response efforts. Measurements of ground surface displacement during an earthquake (i.e. co-seismic deformation) are useful for determining hypocentre location, fault geometry, rupture dynamics and interactions among neighbouring faults (e.g. Massonnet et al. 1993, Fialko et al. 2002). Measurements of deformation that occurs immediately after an earthquake (i.e. post-seismic deformation) provide important clues to the mechanical properties of the Earth's crust and upper mantle (e.g. Biggs et al. 2009). InSAR also has the potential to map interseismic strain accumulation, and thus could become an important tool for assessing long-term seismic hazards (e.g. Wright et al. 2002, Biggs et al. 2007).

InSAR can be used to map land surface subsidence associated with fluid withdrawal or slow-moving landslides, thereby improving the ability to assess and mitigate adverse consequences (e.g. Singhroy et al. 1998, Bawden et al. 2001, Lu and Danskin 2001). Likewise, InSAR deformation images can depict the movement of glaciers and ice fields, aiding the understanding of global warming effects and impacts on sea level change (Rignot and Thomas 2002). InSAR surface displacement images can even map water-level changes in wetlands to improve assessments of flood hazards ( $\mathrm{Lu}$ and Kwoun 2008). Finally, advanced InSAR processing such as PSInSAR has rendered an improved accuracy in mapping and characterisation of various natural hazards (e.g. Colesanti et al. 2003, 2005, Hilley et al. 2004, Lanari et al. 2004, Farina et al. 2006, Funning et al. 2007, Bell et al. 2008, Novali et al. 2008, Puglisi et al. 2008, Bianchi, 2009).

\subsubsection{Hazards applications of SAR intensity and InSAR coherence maps}

Multi-temporal SAR intensity images can be used to identify landform changes resulting from volcanic eruptions, landslides or large earthquakes - even during periods of bad weather that preclude visual observations. For example, SAR images acquired by several orbiting SARs recorded melting of ice, formation of vents, development of lakes and collapse pits and other geomorphic changes during the 2008 eruption of Okmok (Lu and Dzurisin 2010). In other cases, InSAR coherence images are better suited to map the extent and progression of surface disturbance caused by lava-flow emplacement (Lu et al. 2005) 
or volcanic ashfall (Lu and Dzurisin 2010) and for flood mapping, fire scar mapping and oil slick detection (Rykhus and Lu 2007, 2010).

SAR intensity images and InSAR coherence images have proven useful for mapping land cover types (e.g. Ramsey et al. 2006, Kwoun and Lu 2009) and land cover changes caused by hazardous events (e.g. Ramsey et al. 2009). The all-weather, day-and-night imaging capability of SAR supports the acquisition of timely information during hazardous events. For example, multiple SAR images can be used to map the progression of fire and to estimate fire severity (Rykhus and Lu 2010); InSAR products that characterise changes in SAR backscattering return (both intensity and phase components) are indispensable for precise mapping of fire scar extents and severities. In addition, multitemporal SAR images can be used to infer flooding and map soil moisture changes to assist drought monitoring (Le Hegarat-Mascle et al. 2002, Lu and Meyer 2002, Jackson et al. 2005). Quantitative statistical analysis and fusion of multi-temporal and multipolarised SAR images allow for improved landscape characterisation and change detection (e.g. van Zyl 1989, Rignot et al. 1992, Cloude and Pottier 1997, Lee et al. 1999, Le Hegarat-Mascle 2002, Jackson et al. 2005, Henry et al. 2006).

\subsubsection{Hazards applications of InSAR-derived digital elevation models}

The Shuttle Radar Topographic Mission (SRTM), using a dual-antenna radar interferometer onboard NASA's Space Shuttle Endeavour, created the first-ever near-global dataset of land elevations during an 11-day mission in February 2000 (Farr et al. 2007). SRTM data have been used extensively as a base layer in hazards-related Geographic Information Systems (GIS) and to model natural hazards. For example, a DEM is needed to simulate potential mudflows (lahars) that are commonly associated with volcanic eruptions, large earthquakes and flooding caused by heavy rainfall (Iverson et al. 1998). Timely DEM images can be critical for characterising hazards associated with earthquakes, volcanic eruptions, landslides, flooding, snow/ice avalanches and other processes.

\section{Fusion of SAR/InSAR with optical and other images for natural hazards characterisation}

\subsection{Fusion of InSAR, optical images and other data to improve the accuracy of deformation measurements}

Improving the accuracy of InSAR deformation maps is critical for monitoring the subtle ground surface deformation induced by natural hazards. A significant error source in repeat-pass InSAR deformation measurements is the atmospheric delay anomaly (Zebker et al. 1997). Differences in atmospheric temperature, pressure and water vapour content at two observation times can cause differing path delays and consequent anomalies in an InSAR deformation image. Atmospheric delay anomalies can reduce the accuracy of InSAR-derived deformation measurements from several millimetres under ideal conditions to a few centimetres under more typical conditions, thus obscuring subtle changes that could hold clues to the cause of the deformation. The difficulty with estimating water vapour conditions with the needed accuracy and spatial density is an important limiting factor in deformation monitoring with InSAR. Three techniques have been proposed to estimate the water -vapour content and remedy its effect on deformation interferograms. 
The first method is to estimate water vapour concentrations in the target area at the times of SAR image acquisitions using short-term predictions from operational weather models that can simulate or predict mesoscale and regional-scale atmospheric circulation (e.g. Foster et al. 2006). Predicted atmospheric delays from the weather model are used to generate a synthetic interferogram that is subtracted from the observed interferogram, thus reducing atmospheric delay artefacts and improving the ability to identify any remaining ground deformation signal (Figure 4). The problem with this approach is that the current weather models have much coarser resolution (a few kilometres) than InSAR measurements (tens of metres). This deficiency can be remedied to some extent by integrating weather models with high resolution atmospheric measurements, but this approach requires intensive computation.

The second method is to estimate water vapour concentration from continuous Global Positioning System (CGPS) observations in the target area. CGPS is capable of retrieving precipitable water vapour content along the satellite-to-ground LOS with an accuracy that corresponds to 1-2 mm of surface displacement (Bevis et al. 1992, Niell et al. 2001). The spatial resolution (i.e. station spacing) of local or regional CGPS networks is typically a several kilometres to a few tens of kilometres, which is sparse relative to the decimetrescale spatial resolution of SAR images. Therefore, spatial interpolations that take into account the covariance properties of CGPS zenith wet delay (ZWD) measurements and the effect of local topography are required. Jarlemark and Elgered (1998) applied a topography-independent, turbulence-based method to spatially interpolate ZWD values. In a follow-up study, Emardson et al. (2003) found that the spatio-temporal average variance of water vapour content depends not only on the distance between GPS observations, but also on the height difference between stations (i.e. topography). These and other studies led to a topography-dependent turbulence model for InSAR atmospheric correction using ZWD values from CGPS data (Li et al. 2005).

The third approach to correcting atmospheric delay anomalies in InSAR observations is to utilise water vapour measurements from optical satellite sensors such as the Moderate Resolution Imaging Spectroradiometer (MODIS), Advanced Spaceborne Thermal
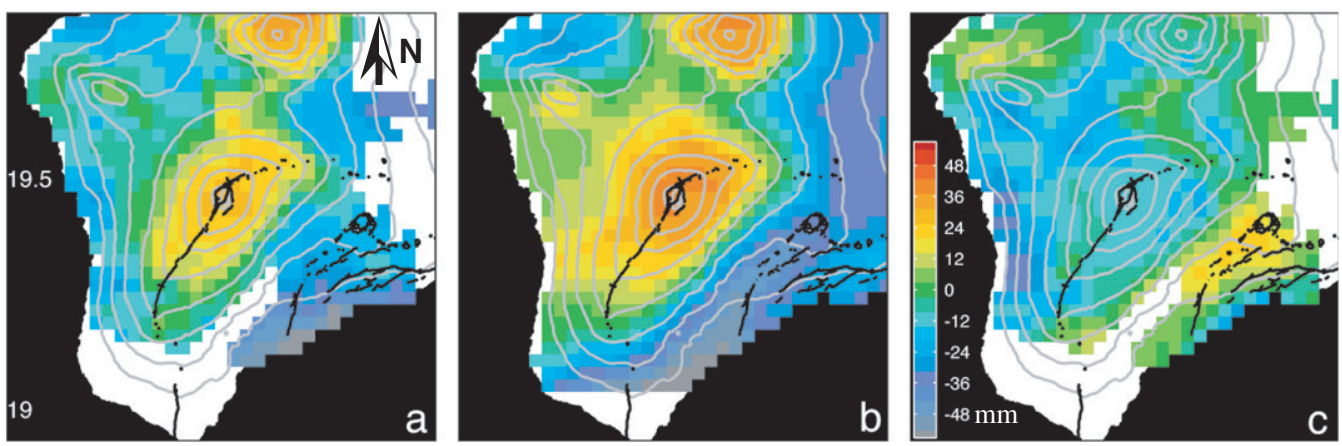

Figure 4. Example of the fusion of InSAR and weather model data to remove atmospheric artifacts to improve InSAR deformation measurements. (a) Original InSAR image of Kilauea Volcano, Hawaii, from SAR images acquired on 29 September and 3 November 2003. (b) Theoretical atmospheric delay anomalies at the times of the SAR image acquisitions derived from a weather model that is used to simulate mesoscale and regional-scale atmospheric circulation. (c) InSAR image after the removal of atmospheric delay anomalies by subtracting Figure 1(b) from Figure 1(a). Images are courtesy of J. Foster, University of Hawaii. 
Emission and Reflection Radiometer (ASTER), and European Medium Resolution Imaging Spectrometre (MERIS) (Li et al. 2003). The disadvantage of this method is the requirement of nearly simultaneous acquisitions of SAR and cloud-free optical images.

\subsection{Fusion of InSAR and radar altimeter data to estimate flood volume in wetlands}

Measuring water-level changes in wetlands and, consequently, changes in water storage capacity provides a governing parameter in hydrologic models and is required for the comprehensive assessment of flood hazards (Coe 1998). In-situ measurements of water levels can be cost-prohibitive and insufficient coverage of stage recording instruments can result in poorly constrained estimates of water storage capacity. With frequent coverage over wide areas, satellite sensors can be a cost-effective tool for measuring water storage accurately. Both L-band and C-band InSAR imagery can be used to measure relative water-level changes in river valleys and wetlands (Alsdorf et al. 2000, Lu and Kwoun 2008). This is because flooded forests produce double-bounce returns of radar pulses and allow InSAR coherence to be maintained, so that changes in the height of the water surface beneath vegetation can be monitored (Alsdorf et al. 2000, Lu and Kwoun 2008). However, a repeat-pass InSAR image measures the relative spatial gradient of water-level changes between two time epochs. In other words, from interferometric phase measurements alone, the absolute volumetric change of water storage within a wetland is not derivable without additional constraints. For example, assume that the water level over a wetland moves up or down by a constant amount. The volumetric change water in the wetland can be calculated by multiplying the area of the wetland by the water-level change. However, as is the case for all types of interferograms, InSAR interferograms exhibit $2 \pi$ ambiguity, i.e. they cannot distinguish among phase shifts of $0,2 \pi, 4 \pi, \ldots, 2 n \pi$. As a result, constant water-level change throughout the wetland could be misinterpreted as no water-level change or vice versa. Therefore, to estimate the absolute change in water storage from an InSAR image, an independent measure of absolute water-level change in at least one location in the wetland is required. The estimate will be improved with additional measurements at other locations if the water-level change varies throughout the wetland.

Satellite radar altimetry has been used successfully for absolute water-level monitoring over large inland water bodies and wetlands at coarse spatial resolution (a few hundred metres; Lee et al. 2009). This led to the development of an innovative method to integrate InSAR and satellite radar altimetry measurements to map absolute water-level changes (Lu et al. 2009, Kim et al. 2009). Through the method of retracking individual return waveforms, absolute water-level measurements in wetlands over the altimeter footprint can be derived from radar altimeter data. High-resolution $(\sim 40 \mathrm{~m})$ relative water-level changes measured with InSAR can be integrated with lower-resolution absolute waterlevel changes measured with radar altimetry to calculate total water storage changes in wetlands (Figure 5). Of course, the role of the altimeter can be replaced by ground-based water-level gauge stations or by other satellite instruments. Optimised radar images with short repeat-pass acquisitions from multiple satellite sensors, combined with available in situ and remote sensing measurements of absolute water-level changes, can significantly improve the characterisation of surface water hydraulics, hydrological modelling predictions and the assessment of future flood events in wetlands (Lu et al. 2009, Kim et al. 2009). 

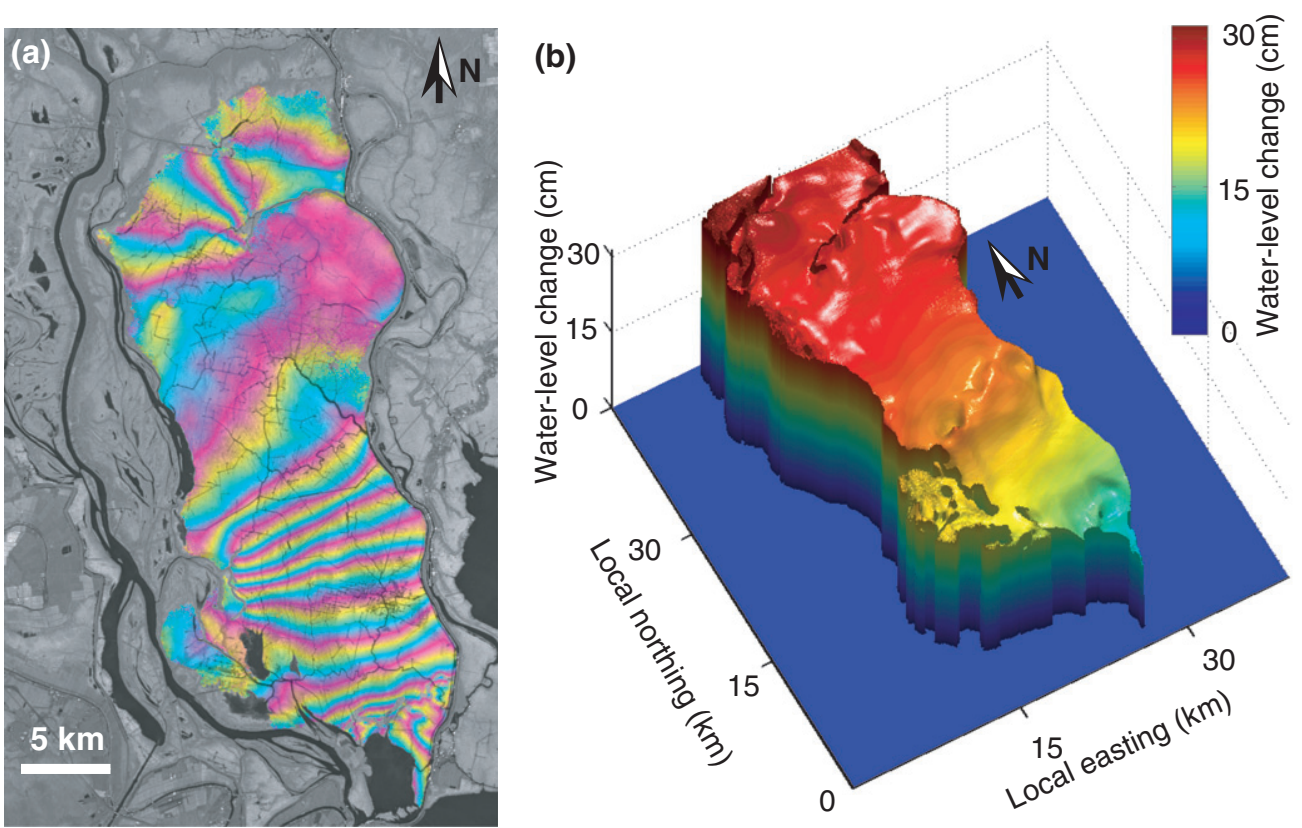

Figure 5. Example of fusing InSAR and satellite radar altimeter data to map flood volume in wetlands. (a) C-band $(\lambda=-5.7 \mathrm{~cm})$ interferogram produced from RADARSAT-1 images, showing heterogeneous water-level changes in swamp forests in coastal Louisiana (southeastern USA) between 22 May and 15 June 2003. The interferometric phase image is draped over the radar intensity image. Each fringe (full-colour cycle) represents a $3.1-\mathrm{cm}$ vertical change in water level. (b) Three-dimensional view of water volume changes derived from the InSAR image combined with radar altimeter and water-level gauge measurements. Presumably, the uneven distribution of water-level changes results from dynamic hydrologic effects in a shallow wetland with variable vegetation cover.

\subsection{Fusion of SAR and optical images}

Various techniques have been proposed to fuse optical and SAR images to obtain information that cannot be extracted from either radar or optical images alone (e.g. Pohl and van Genderen 1998). The objective is to fuse optical (e.g. Landsat) and SAR images while preserving both accurate spectral information from the former and textural information from the latter. Towards this goal, various data fusion techniques have been developed to integrate SAR and optical images. Solberg et al. (1994) applied a statistical approach of Bayesian formulation to fuse SAR and Landsat images for land cover classification. The fusion model could take into account the temporal attribute and their changes of multi-temporal image sources. The authors demonstrated that the fusion of ERS-1 SAR and Landsat TM images provided a significant improvement on classification accuracy. Serpico and Roli (1995) and Bruzzone et al. (1999) used neural network fusion techniques for land cover characterisation. Overall classification accuracy by fusing SAR and optical images can be about $10-15 \%$ higher than the classification result without fusion. By exploiting spatial context between neighbouring pixels in an image and temporal dependencies between different images, Solberg et al. (1996) proposed a fusion model based on Markov random field to integrate remotely sensed data including SAR images. 
Other data fusion techniques have also been used to fuse SAR and optical images. Haack et al. (2002) applied a principal component analysis approach to fuse Landsat TM and Radarsat-1 images for urban land cover characterisation. Gamba and Houshmand (2002) combined SAR, LIDAR and aerial images to extract land cover and DEM. Alparone et al. (2004) developed an intensity modulation algorithm that utilised the ratio between the despeckled SAR intensity image and its wavelet decomposition (e.g. Yocky 1996) to fuse SAR and Landsat ETM + images. Chibani (2006) integrated the modified Brovey transformation and wavelet decomposition to fuse SAR and SPOT images. Xie and Keller (2006) applied a hue-saturation-value transformation to integrate SAR and Landsat $\mathrm{ETM}+$ images to fuse surface roughness from SAR images with surface spectral reflectivity from Landsat images. Hong et al. (2009) fused high-resolution SAR and low-resolution multi-spectral images by integrating wavelet and intensity-hue-saturation (e.g. Chen et al. 2003, Tu et al. 2004) transformations to maintain the spatial details of SAR images as well as preserve the spectral content of the multi-spectral images. By generalising Hong et al. (2009) techniques, Zhang (2009) developed an adjustable SAR and multi-spectral fusion allowing users to fuse SAR and multi-spectral images at a user-desired level for diverse geospatial applications. All these techniques demonstrated that fusion products would reveal features that were not evident in the original single-source images and would provide improved landscape monitoring and change detection. Below, we highlight two examples to illustrate the fusion of SAR and optical images to characterise natural hazards.

\subsubsection{Fusion of SAR and optical images to map flood inundation}

An illustrative example of SAR and optical image fusion is flood inundation mapping (e.g. Hess et al. 1995, Tholey et al. 1997, Brakenridge et al. 1998, Townsend and Walsh 1998, Bourgeau-Chavez et al. 2001, Townsend 2002, Wang 2002, Ahtonen et al. 2005, Dey et al . 2008, Mason et al. 2009, Ramsey et al. 2009, Schumann et al. 2009, Bwangoy et al. 2010). Typically, during-event SAR images and pre-event optical images are fused to produce a flood inundation map. In SAR images, both specular and double-bounce interactions can be useful for delineating the extent of flooding. During calm weather, water acts as a specular reflector for an incident SAR signal, resulting in very low backscatter returns that can be used to map flooded areas. Turbulent weather can generate waves that produce high backscatter returns, which also can be useful if non-flooded areas are 'radar dark' (i.e. low backscatter). In the first case, if flooding occurs in areas with vegetation, a phenomenon known as a 'double bounce' interaction may occur. In a double bounce interaction, the SAR signal initially is reflected away from the sensor by the water's surface towards a tree bole or other vertical structure, and then is reflected a second time back towards the sensor. The double bounce interaction results in a higher backscatter return when the land surface is not flooded, and therefore is important for identifying flooding in forested and urban areas. Discrimination between types of SAR interactions requires information relating to land cover conditions, which can be derived from a pre-event optical image (Rykhus and Lu 2007). Multi-temporal SAR images can be used to map the progression of flooding over time and the maximum flood extent (Figure 6).

\subsubsection{Fusion of SAR and optical images to map vegetation structure and its change}

There are generally two groups of methods used to estimate vegetation structure from SAR images. One is to utilise SAR backscattering returns from single-polarisation or 


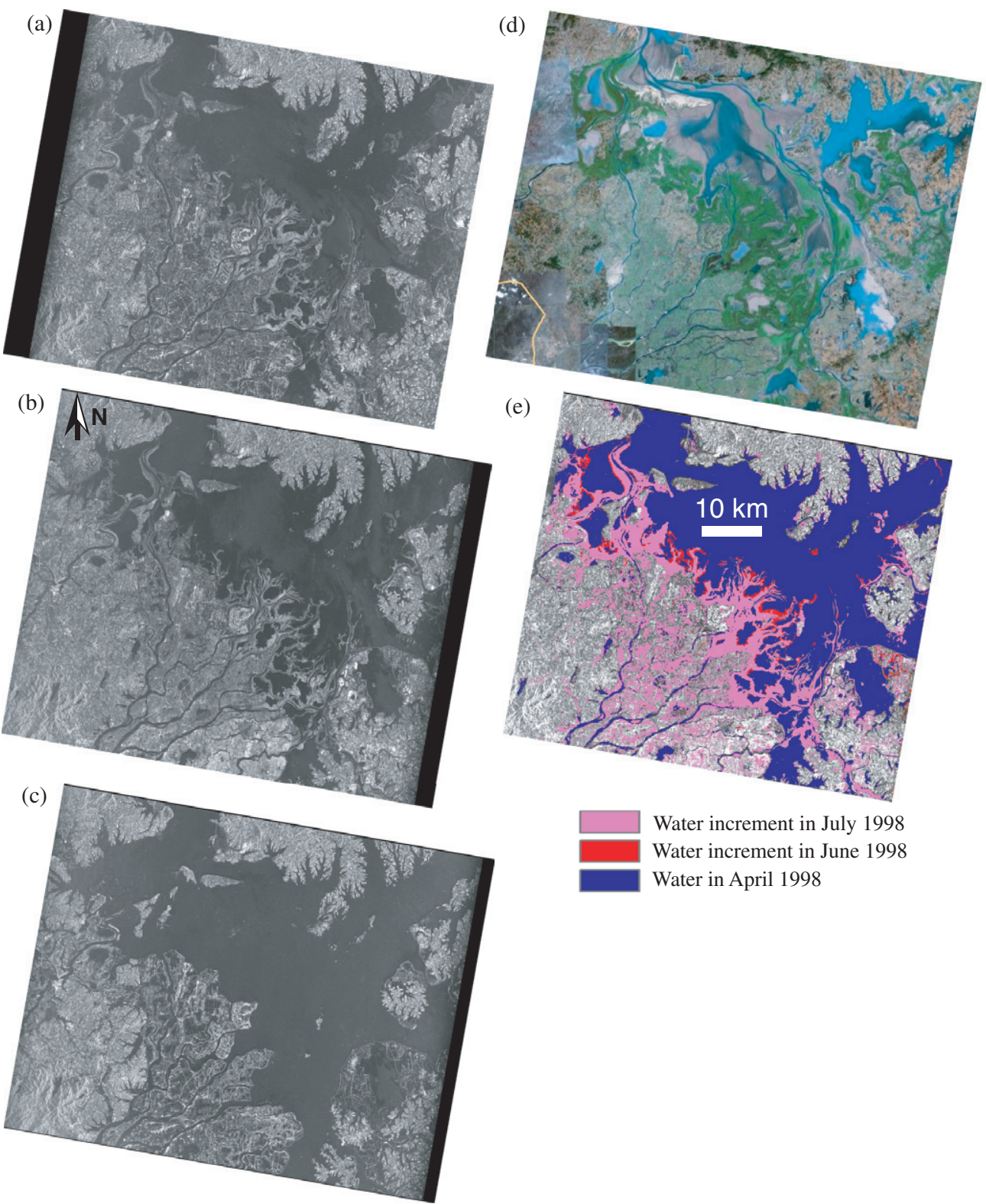

Figure 6. Example of fusion of SAR and optical images for flood mapping over Poyang Lake, China. (a) JERS-1 SAR image acquired on 27 April 1998, before the flood. (b) JERS-1 SAR image acquired on 10 June 1998, near the beginning of the flood. (c) JERS-1 SAR image acquired on 24 July 1998, during the peak of the flood. (d) Optical image of the area covered by SAR images (courtesy Google Earth). (e) Map of flood inundation on the dates of SAR image acquisitions.

multiple-polarisation SAR images to infer vegetation structure and attributes (e.g. Dobson et al. 1995, Saatchi et al. 2007). Ground truth and optical images are needed to establish the relationship between radar backscattering and vegetation structure. The other is to use InSAR products (both phase and coherence images) to estimate vegetation structure 
(e.g. Crawford 1999, Slatton et al. 2001, Simard et al. 2006, Walker et al. 2007). Most spaceborne SARs such as those onboard ERS-1, ERS-2, JERS-1 and RADARSAT-1 are single-polarised radars (i.e. radar signals are transmitted and received with vertical or horizontal polarisation). Sensors of this type only partially capture the scattering properties of targets on the surface. Data from a fully-polarised radar (i.e. radar signals are transmitted and received with both vertical and horizontal polarisations), such as those onboard the Japanese ALOS satellite and future radar satellites, can be related to the signatures of known elemental targets, making it possible to infer the type of scattering that is taking place (e.g. Cloude and Pottier 1996, Touzi et al. 2004). Polarisation signatures of the vegetation canopy, the bulk volume of vegetation and the ground are different and can be separated using polarimetric analysis. An optimisation procedure can be employed to maximise interferometric coherence between two polarimetric radar images, thereby reducing the effect of baseline and temporal decorrelation in the interferogram. Then, using a coherent target decomposition approach that separates distinctive backscattering returns from the canopy top, the bulk volume of vegetation and the ground surface, one can derive height differences between physical scatterers with differing scattering characteristics (Cloude and Papathanassiou 1998). Physical radar backscattering models for different vegetation types can be developed to calculate the canopy height, the bare-Earth topography and other parameters based on measurements from polarimetric InSAR images.

\section{Emerging SAR fusion technologies and applications}

One of the leading-edge research developments involving fusion of multiple SAR images is SAR tomography (Reigber and Moreira 2000). A single SAR image maps 3-D characteristics of ground resolution elements into the 2-dimensional (2-D) SAR imaging plane (i.e. the slant range and azimuth directions). For vegetated terrain, the backscattering return at a SAR image pixel represents the projection of 3-D distributed targets within the resolution element. Repeat-pass SAR images can be combined interferometrically to generate an InSAR image, which provides the average height of targets of the ground resolution element. For bare surface, the height in each InSAR pixel represents the average height of the targets (i.e. the mean phase centre of targets) within the resolution element. For vegetated terrain, the InSAR height corresponds to the effective, average height of 3-D structure of vegetation within the imaging area. Therefore, the 3-D structure of scatterers within a SAR resolution element cannot be obtained. The aforementioned polarimetric InSAR can allow the separation of phase centres between targets within the resolution element if the polarimetric signatures of the targets are unique and can be separated. However, when the polarimeric backscattering signatures of targets are similar, the polarimetric InSAR cannot resolve the 3-D vegetation structure either. Enlightened by the computer-aided X-ray tomography (CT) concept in medical imaging, Reigber and Moreira (2000) introduced the construction of 3-D distribution of dominant scatters with a resolution element through multiple-baseline, multiple-InSAR imaging - SAR tomography imaging. In essence, SAR tomography imaging utilises the variation of spatial baselines from multiple SAR images to construct a second synthetic aperture in the direction perpendicular to both the SAR LOS direction and the azimuth direction to resolve vertical structure of targets in a resolution element (e.g. Reigber and Moreira 2000, Fornaro et al. 2005, Lombardini 2005, Nannini et al. 2009). Fusion of SAR imagery 
through SAR tomography processing has the potential to improve the estimates of vegetation structure dramatically, and even to alleviate geometric distortion (e.g. layover effect) that plagues traditional SAR images of steep terrain. Therefore, SAR tomography has a great potential to better characterise and monitor landscape changes due to natural hazards.

New SAR image fusion techniques almost surely will arise with the birth of new satellite missions. Deformation, Ecosystem Structure and Dynamics of Ice (DESDynI), a SAR mission proposed by NASA, is a direct application of SAR and LIDAR image fusion (Zebker et al. 2007). A LIDAR system transmits pulses of laser light downward and receives various reflections from the surfaces of leaves, other vegetation elements and the ground. The round-trip travel times are directly related to the heights of the reflecting vegetation elements and therefore to vegetation structure. However, LIDAR coverage usually is restricted to near-nadir incidence angles and thus requires interpolation between observed points to obtain large-scale estimates of vegetation structure. To accomplish this, DESDynI uses an L-band SAR to sweep the landscape including the LIDAR footprint. The polarimetric SAR returns and derived InSAR products are then used to extend the LIDAR measurements to full spatial coverage on a global scale. Fusion of LIDAR and SAR/InSAR measurements will enable the monitoring of vegetation disturbance due to logging and deforestation, as well as to fire, volcanic eruption and other hazardous events.

Besides the DESDynI mission, two other exciting missions are planned. The first is the TerraSAR-X tandem mission for digital elevation measurements (TanDEM-X) to be launched in mid-2010 by the German Aerospace Agency. TanDEM-X is a new high resolution InSAR mission that relies on an innovative flight formation of two tandem TerraSAR-X satellites to produce DEMs on a global scale with an accuracy better than SRTM (Krieger et al. 2007). The DEM provided by TanDEM-X will be very useful for characterising, monitoring and modelling various hazardous events that affect landscape topography. TanDEM-X will also enable precise mapping of ocean currents by fusing two SAR images steered in the along-track direction; the resulting product will be invaluable for monitoring extreme waves and ocean hazards. In addition, TanDEM-X will provide data to assess the utility of new methods, including bi-static multi-angle SAR imaging, digital beam formation and polarimetric InSAR, for monitoring the landscape and its changes. Another planned mission of special interest here is the European Space Agency's BIOMASS mission (http://www.cesbio.ups-tlse.fr/us/indexbiomass.html). BIOMASS is a single satellite P-band SAR, designed to provide continuous global interferometric and polarimetric SAR observations of forested areas. BIOMASS aims to determine, for the first time and in a consistent manner, the distribution and temporal changes of forest structure at a global scale, enabling quantitative, 3-D (areal extent and height) assessment of vegetation changes caused by natural disasters and human activities.

Another exciting development in the next decade will be the deployment of several constellations of SAR satellites to enhance the current capabilities for natural hazards monitoring and mitigation. The ESA Sentinel-1 mission (Floury et al. 2008) is a constellation of two C-band SARs designed to supply all-weather day-and-night imagery to a number of operational Earth observation services. An explicit goal of the mission is to support of disaster management. The two-satellite constellation promises 6-day exact repeat observations and data product quality better than the previous ERS-1, ERS-2 and Envisat SARs. The CSA's RADARSAT Constellation (RADARSAT-C; http:// www.asc-csa.gc.ca/eng/satellites/radarsat/default.asp) represents continued evolution of the successful RADARSAT-1 and RADARSAT-2 missions, with an objective of ensuring 
data continuity, improved operational use of SAR, and improved system reliability. The three-satellite configuration will provide complete daily coverage of Canada's land surface and adjacent oceans, as well as daily access to $95 \%$ of the globe. The JAXA ALOS followon mission (http://www.alos.jp/pdf/ALOS-2_ISTS2009.pdf) has been proposed to extend L-band SAR data acquisition that began with JERS-1 and PALSAR. Together, these constellations will constitute a fleet of spaceborne SAR sensors that combined with innovative airborne SAR instruments (e.g. UAVSAR; Hensley et al. 2005), will make it possible to monitor natural hazards globally in near real-time.

\section{Concluding remarks}

SAR/InSAR image fusion is one of the fastest growing fields in remote sensing, SAR signal processing and Earth science. Timely observations of precise land surface topography and time-transient surface changes will accelerate development of predictive models that can anticipate the effects of natural processes such as volcanic eruptions, earthquakes, landslides and wildfires. In addition, SAR/InSAR fusion products will provide tools to better characterise the role of glaciers and ice sheets in sea-level rise as a result of global warming, and the contributions of groundwater, surface water, soil moisture and snow to the global fresh water budget. Furthermore, SAR/InSAR tomography will offer the capability of imaging the 3-D structure of vegetation on a global scale for improved characterisation and management of Earth's resources. With more operational platforms available for timely data acquisitions, SAR and InSAR coupled with state-of-the-art image fusion and data mining technologies (Datcu et al. 2003) - will continue to address and provide solutions to many scientific questions related to natural hazards.

\section{Acknowledgements}

ERS-1/-2 and Envisat, RADARSAT-1 and JERS-1 SAR images are copyrighted by ESA, CSA and JAXA, respectively, and were provided by the Alaska Satellite Facility (ASF) and ESA. This study was supported by funding from the NASA Earth Surface and Interior Programme, USGS Land Remote Sensing Programme and USGS Volcano Hazards Programme. Technical reviews and edits by N. Wood, O. Kwoun and W. Scott are greatly appreciated. This study has been benefited from the discussions with many colleagues, particularly O. Kwoun, R. Rykhus, C.W. Lee, C. Wicks, J. Biggs, T. Wright and others.

\section{References}

Ahtonen, P., et al., 2005. SAR and optical based algorithms for estimation of water bodies, technical report, FloodMan Project. Available from: http://projects.itek.norut.no/floodman/ ResultsFloodman.htm

Alparone, L., et al., 2004. Landsat ETM+ and SAR image fusion based on generalized intensity Modulation. IEEE Transactions on Geosciences and Remote Sensing, 42, 2832-2839.

Alsdorf, D., et al., 2000. Interferometric radar measurements of water-level changes on the Amazon floodplain. Nature, 404, 174-177.

Baek, S., et al., 2005. Digital elevation model of King Edward VII Peninsula, West Antarctica, from SAR interferometry and ICESat laser altimetry. IEEE Geoscience and Remote Sensing Letters, $2,413-417$. 
Bawden, G., et al., 2001. Tectonic contraction across Los Angeles after removal of groundwater pumping effects. Nature, 412, 812-815.

Bell, J., et al., 2008. Permanent scatterer InSAR reveals seasonal and long-term aquifer-system response to groundwater pumping and artificial recharge. Water Resources Research, 44, 1-18.

Berardino, P., et al., 2002. A new algorithm for surface deformation monitoring based on small baseline differential SAR interferograms. IEEE Trans. Geoscience Remote Sensing, 40, 2375-2383.

Bevis, M., et al., 1992. GPS meteorology: remote sensing of the atmospheric water vapor using the Global Positioning System. Journal of Geophysical Research, 97, 15787-15801.

Bianchi, M., 2009. Terrain deformation monitoring with PSInSAR [online]. The 2nd GlobVolcano User Workshop, San Jose, Costa Rica. Available from: http://www.globvolcano.org

Biggs, J., et al., 2007. Multi-interferogram method for measuring interseismic deformation: Denali fault, Alaska. Geophysical Journal International, 173, 1165-1179.

Biggs, J., et al., 2009. The postseismic response to the (2002) M7.9 Denali fault earthquake: constraints from InSAR. Geophysical Journal International, 176, 353-367.

Bourgeau-Chavez, L., et al., 2001. Analysis of space-borne SAR data for wetland mapping in Virginia riparian ecosystems. International Journal of Remote Sensing, 22, 3665-3687.

Brakenridge, G., Tracy, B., and Knox, J., 1998. Orbital remote sensing of a river flood wave. International Journal of Remote Sensing, 19, 1439-1445.

Bruzzone, L., Prieto, D., and Serpico, S., 1999. A neural-statistical approach to multitempral and multisource remote-sensing image classification. IEEE Transactions on Geosciences and Remote Sensing, 37, 1350-1359.

Bwangoy, J.R., et al., 2010. Wetland mapping in the Congo Basin using optical and radar remotely sensed data and derived topographical indices. Remote Sensing of Environment, 114, 73-86.

Carande, R., 1994. Estimating ocean coherence time using dual-baseline interferometric synthetic aperture radar. IEEE Transactions on Geoscience and Remote Sensing, 32, 846-854.

Chen, C., Hepner, G., and Foster, R., 2003. Fusion of hyperspectral and radar data suing the HIS transformation to enhance urban surface features. ISPRS Journal of Photogrammetry and Remote Sensing, 58, 19-30.

Chibani, Y., 2006. Additive integration of SAR features into multispectral SPOT images by means of the à trous wavelet decomposition. ISPRS Journal of Photogrammetry and Remote Sensing, 60 (5), 306-314.

Cloude, S. and Papathanassiou, K., 1998. Polarimetric SAR interferometry. IEEE Transactions on Geoscience and Remote Sensing, 36, 1551-1565.

Cloude, S. and Pottier, E., 1996. A review of target decomposition theorems in radar polarimetry. IEEE Transactions on Geoscience and Remote Sensing, 34, 498-518.

Cloude, S. and Pottier, E., 1997. An entropy based classification scheme for land applications of polarimetric SAR. IEEE Transactions on Geoscience and Remote Sensing, 35, 68-78.

Coe, M., 1998. A linked global model of terrestrial hydrologic processes: simulation of the modern rivers, lakes, and wetlands. Journal of Geophysical Research, 103, 8885-8899.

Colesanti, C., et al., 2003. Monitoring landslides and tectonic motions with the permanent scatterers technique. Engineering Geology, 68, 3-14.

Colesanti, C., et al., 2005. Detection of mining related ground instabilities using the permanent scatterers technique - a case study in the east of France. International Journal of Remote Sensing, 26, 201-207.

Crawford, M., 1999. Fusion of airborne polarimetric and interferometric SAR for classification of coastal environments. IEEE Transactions on Geoscience and Remote Sensing, 37, 1306-1313.

Curlander, J. and McDonough, R., 1991. Synthetic aperture radar systems and signal processing. New York: John Wiley \& Sons.

Datcu, M., et al., 2003. Information mining in remote sensing image archives: system concepts. IEEE Transactions on Geoscience and Remote Sensing, 41, 2923-2936. 
Davis, P.M., 1986. Surface deformation due to inflation of an arbitrarily oriented triaxial ellipsoidal cavity in an elastic half-space, with reference to Kilauea Volcano, Hawaii. Journal of Geophysical Research, 91, 7429-7438.

Dey, C., Jia, X., and Fraser, D., 2008. Decision fusion for reliable flood mapping using remote sensing images. Proceedings of digital image computing: techniques and applications, 5, 184-190 (doi: 10.1109/DICTA.2008.65).

Dobson, M.C., et al., 1995. Estimation of forest biophysical characteristics in Northern Michigan with SIR-C/X-SAR. IEEE Transactions on Geoscience and Remote Sensing, 33, 877-895.

Dzurisin, D., 2003. A comprehensive approach to monitoring volcano deformation as a window on eruption cycle. Review of Geophysics, 41, 1001, (29 pages), doi: 10.1029/2001RG000107.

Dzurisin, D., 2007. Volcano deformation - geodetic monitoring techniques. Chichester: SpringerPraxis Publishing Ltd.

Emardson, T., Simons, M., and Webb, F., 2003. Neutral atmospheric delay in interferometric synthetic aperture radar applications: statistical description and mitigation. Journal of Geophysical Research, 108(B5), 2231.

Farina, P., et al., 2006. Permanent scatterers for landslide investigations: outcomes from the ESA-SLAM project. Engineering Geology, 88, 200-217.

Farr, T.G., et al., 2007. The shuttle radar topography mission. Review of Geophysics, 45, RG2004.

Ferretti, A., Prati, C., and Rocca, F., 1999. Multibaselime InSAR DEM reconstruction: the wavelet approach. IEEE Transactions on Geoscience and Remote Sensing, 37 (2), 705-715.

Ferretti, A., Prati, C., and Rocca, F., 2001. Permanent scatterers in SAR interferometry. IEEE Transactions on Geoscience and Remote Sensing, 39, 8-20.

Ferretti, A., et al., 2007. Submillimeter accuracy of InSAR time series: experimental validation. IEEE Transactions on Geoscience and Remote Sensing, 45, 1142-1153.

Fialko, Y., Khazan, Y., and Simons, M., 2001. Deformation due to a pressurized horizontal circular crack in an elastic half-space, with applications to volcano geodesy. Geophysical Journal International, 146, 181-190.

Fialko, Y., et al., 2002. Deformation on nearby faults induced by the 1999 Hector Mine earthquake. Science, 297, 1858-1862.

Floury, N., et al., 2008. ESA sentinel-1 mission and products. 37th COSPAR Scientific Assembly, 13-20 July 2008, Montréal, Canada.

Fornaro, G., Lombardini, F., and Serafino, F., 2005. Three-dimensional multipass SAR focusing: experiments with long-term spaceborne data. IEEE Transactions on Geoscience and Remote Sensing, 43 (4), 702-714.

Foster, J., et al., 2006. Mitigating atmospheric noise for InSAR using a high-resolution weather model. Geophysical Research Letters, 33, L16304.

Funning, G., et al., 2007. Creep on the Rodgers Creek fault, northern San Francisco Bay area from a 10 years PS-InSAR dataset. Geophysical Research Letters, 34, L(1930)6, 1-5.

Gamba, P. and Houshmand, B., 2002. Joint analysis of SAR, LIDAR and aerial imagery for simultaneous extraction of land cover, DTM and 3D shape of buildings. International Journal of Remote Sensing, 23, 4439-4450.

Goldstein, R. and Zebker, H., 1987. Interferometric radar measurements of ocean surface currents. Nature, 328, 707-709.

Gray, L. and Farris-Manning, P., 1993. Repeat-pass interferometry with airborne synthetic aperture radar. IEEE Transactions on Geoscience and Remote Sensing, 31, 180-191.

Guarnieri, A.M. and Rocca, F., 1999. Combination of low- and high-resolution SAR images for differential interferometry. IEEE Transactions on Geoscience and Remote Sensing, 37, 2035-2049.

Haack, B., et al., 2002. Radar and optical data comparison/integration for urban delineation: a case study. Photogrammetric Engineering and Remote Sensing, 68, 1289-1296.

Henry, J., et al., 2006. Envisat multipolarized ASAR data for flood mapping. International Journal of Remote Sensing, 27, 1921-1929. 
Hensley, S., et al., 2005. Status of a UAVSAR designed for repeat pass interferometry for deformation measurements. IEEE MTTS International Microwave Symposium Digest, 3, $1453-1456$.

Hess, L., et al., 1995. Delineation of inundated area and vegetation along the Amazon floodplain with the SIR-C synthetic aperture radar. IEEE Transactions on Geoscience and Remote Sensing, 33, 896-904.

Hilley, G., et al., 2004. Dynamics of slow-moving landslides from permanent scatterer analysis. Science, 304, 1952-1955.

Holzner, J. and Bamler, R., 2002. Burst-mode and scanSAR interferometry. IEEE Transactions on Geoscience and Remote Sensing, 40, 1917-1934.

Hong, G., Zhang, Y., and Mercer, B., 2009. A wavelet and HIS integration method to fuse high resolution SAR and moderate resolution multispectral images. Photogrammetric Engineering and Remote Sensing, 75 (10), 1-11.

Hooper, A., Segall, P., and Zebker, H., 2007. Persistent scatterer interferometric synthetic aperture radar for crustal deformation analysis, with application to Volcán Alcedo, Galápagos. Journal of Geophysical Research, 112, B07407.

Iverson, R., Schilling, S., and Vallance, J., 1998. Objective delineation of lahar-inundation hazard zones. GSA Bulletin, 110 (8), 972-984.

Jackson, T., et al., 2005. Mapping near-surface soil moisture on regional scale using ERS-2 SAR data. International Journal of Remote Sensing, 22, 4589-4598.

Jarlemark, P.O.J. and Elgered, G., 1998. Characterization of temporal variations in atmospheric water vapor. IEEE Transactions on Geoscience and Remote Sensing, 36, 319-321.

Kim, J., et al., 2009. Integrated analysis of PALSAR/Radarsat-1 InSAR and ENVISAT altimeter for mapping of absolute water level changes in Louisiana wetland. Remote Sensing of Environment, 113, 2356-2365.

Krieger, G., et al., 2007. TanDEM-X: a satellite formation for high-resolution SAR interferometry. IEEE Transactions on Geoscience and Remote Sensing, 45, 3317-3341.

Kwoun, O. and Lu, Z., 2009. Multi-temporal RADARSAT-1 and ERS backscattering signatures of coastal wetlands at southeastern Louisiana. Photogrammetric Engineering and Remote Sensing, 75 (5), 607-617.

Lanari, R., et al., 2004. Satellite radar interferometry time series analysis of surface deformation for Los Angeles, California. Geophysical Research Letters, 31, 1-5.

Le Hegarat-Mascle, S., et al., 2002. Soil moisture estimation from ERS/SAR data: toward an operational methodology. IEEE Transactions on Geoscience and Remote Sensing, 40, 2647-2658.

Lee, J., et al., 1999. Unsupervised classification of polarimetric SAR images by applying target decomposition and complex wishart distribution. IEEE Transactions on Geoscience and Remote Sensing, 37 (5), 2249-2258.

Lee, H., et al., 2009. Louisiana wetland water level monitoring using retracked TOPEX/POSEIDON altimetry. Marine Geodesy, 32 (3), 284-302.

Lee, C., et al., 2010. Surface deformation of Augustine Volcano (Alaska), 1992-2005, from multipleinterferogram processing using a refined SBAS InSAR approach. USGS Professional Paper (in press).

Li, Z., Muller, J.P., and Cross, P., 2003. Comparison of precipitable water vapor derived from radiosonde, GPS, and moderate-resolution imaging spectroradiometer measurements. Journal of Geophysical Research, 108 (D20), 4651.

Li, Z., et al., 2005. InSAR atmospheric correction: GPS topography-dependent turbulence model (GTTM). Journal of Geophysical Research, 110, B02404.

Lombardini, F., 2005. Differential tomography: a new framework for SAR interferometry. IEEE Transactions on Geoscience and Remote Sensing, 43 (1), 37-44.

Lu, Z. and Danskin, W., 2001. InSAR analysis of natural recharge to define structure of a groundwater basin, San Bernardino, California. Geophysical Research Letters, 28, 2661-2664. 
Lu, Z. and Freymueller, J., 1998. Synthetic aperture radar interferometry coherence analysis over Katmai volcano group, Alaska. Journal of Geophysical Research, 103, 29887-29894.

Lu, Z. and Meyer, D., 2002. Study of high SAR backscattering due to an increase of soil moisture over less vegetated area: its implication for characteristic of backscattering. International Journal of Remote Sensing, 23 (6), 1065-1076.

Lu, Z., et al., 2002. Magmatic inflation at a dormant Strato volcano: 1996-98 activity at Mount Peulik Volcano, Alaska, revealed by satellite radar interferometry. Journal of Geophysical Research, 107, 2134.

Lu, Z., et al., 2003. Estimating lava volume by precision combination of multiple baseline spaceborne and airborne interferometric synthetic aperture radar: the 1997 eruption of Okmok volcano, Alaska. IEEE Transactions on Geoscience and Remote Sensing, 41, $1428-1436$.

Lu, Z., Masterlark, T., and Dzurisin, D., 2005. Interferometric synthetic aperture radar (InSAR) study of Okmok Volcano, Alaska, 1992-2003: magma supply dynamics and postemplacement lava flow deformation. Journal of Geophysical Research, 110, B02403.

Lu, Z., 2007. InSAR imaging of volcanic deformation over cloud-prone areas - Aleutian Islands. Photogrammetric Engineering and Remote Sensing, 73, 245-257.

Lu, Z., Kwoun, O., and Rykhus, R., 2007a. Interferometric synthetic aperture radar (InSAR): its past, present and future. Photogrammetric Engineering and Remote Sensing, 73, 217-221.

Lu, Z., et al., 2007b. Diverse deformation patterns of Aleutian volcanoes from satellite interferometric synthetic aperture radar (InSAR), In: J. Eichelberger, et al. eds. Volcanism and subduction: the Kamchatka region, American Geophysical Union Geophysical Monograph Series 172, 249-261.

Lu, Z. and Kwoun, O., 2008. RADARSAT-1 and ERS interferometric analysis over southeastern coastal Louisiana: implication for mapping water-level changes beneath swamp forests. IEEE Transactions on Geoscience and Remote Sensing, 46, 2167-2184.

Lu, Z., et al., 2009. Helmand river hydrologic studies using ALOS PALSAR InSAR and ENVISAT altimetry. Marine Geodesy, 32 (3), 320-333.

Lu, Z. and Dzurisin, D., 2010. Ground surface deformation patterns, magma supply, and magma storage at Okmok volcano, Alaska, inferred from InSAR analysis: II: co-eruptive deflation, July-August 2008. Journal of Geophysical Research, 115, (13 pages), doi:10.1029/ 2009JB006970.

Madsen, S., Zebker, H., and Martin, J., 1993. Topographic mapping using radar interferometry: processing techniques. IEEE Transactions on Geoscience and Remote Sensing, 31, 246-256.

Mason, D., et al., 2010. Flood detection in urban areas using TerraSAR-X. IEEE Transactions on Geoscience and Remote Sensing, 48, 882-894.

Massonnet, D., et al., 1993. The displacement field of the landers earthquake mapped by radar interferometry. Nature, 364, 138-142.

Massonnet, D. and Feigl, K., 1998. Radar interferometry and its application to changes in the Earth's surface. Reviews of Geophysics, 36, 441-500.

Mogi, K., 1958. Relations between the eruptions of various volcanoes and the deformations of the ground surface around them. Bulletinof the Earthquake Research Institute of University of Tokyo, 36, 99-134.

Nannini, M., Scheiber, R., and Moreira, A., 2009. Estimation of the minimum number of tracks for SAR tomography. IEEE Transactions on Geoscience and Remote Sensing, 47, 531-543.

Niell, A., et al., 2001. Comparison of measurements of atmospheric wet delay by radiosonde, water vapor radiometer, GPS, and VLBI. Journal of Atmospheric and Oceanic Technology, 18, 830-850.

Novali, F., et al., 2008. PSInSAR analysis monitors Lake Sarez displacement. GIS Development, 12, 38-41.

Okada, Y., 1985. Surface deformation due to shear and tensile faults in a half-space. Bulletin of the Seismological Society of America, 75, 1135-1154. 
Pohl, C. and van Genderen, J., 1998. Multisensor image fusion in remote sensing: concepts, methods and applications. International Journal of Remote Sensing, 19, 823-854.

Puglisi, G., et al., 2008. Dynamics of Mt. Etna before, during and after the July-August 2001 eruption inferred from GPS and differential SAR interferometry. Journal of Geophysical Research, 113, 1-20.

Ramsey, E. III, et al., 2006. Multiple baseline radar interferometry applied to coastal landscape classification and changes. GIScience and Remote Sensing, 43, 283-309.

Ramsey, E., et al., 2009. Satellite optical and radar data used to track wetland forest impact and short-term recovery from Hurricane Katrina. Wetlands, 29 (1), 66-79.

Reigber, A. and Moreira, A., 2000. First demonstration of airborne SAR tomography using multibaseline L-band data. IEEE Transactions on Geoscience and Remote Sensing, 38, 2142-2152.

Rignot, E., Chellappa, R., and Dubois, P., 1992. Unsupervised segmentation of polarimetric SAR data using the covariance matrix. IEEE Transactions on Geoscience and Remote Sensing, 30, $697-705$.

Rignot, E. and Thomas, R., 2002. Mass balance of polar ice sheets. Science, 297, 1502-1506.

Rocca, F., 2007. Modeling interferogram stacks. IEEE Transactions on Geoscience and Remote Sensing, 45, 3289-3299.

Romeiser, R. and Thompson, D., 2000. Numerical study on the along-track interferometric radar imaging mechanism of oceanic surface currents. IEEE Transactions on Geoscience and Remote Sensing, 38, 446-458.

Rosen, P., et al., 2000. Synthetic aperture radar interferometry. Proceedings of IEEE, 88, 333-380.

Ruffino, G., Moccia, A., and Esposito, S., 1998. DEM generation by means of ERS tandem data. IEEE Transactions on Geoscience and Remote Sensing, 36, 1905-1912.

Rykhus, R. and Lu, Z., 2007. Hurricane Katrina flooding and possible oil slicks mapped with satellite imagery, USGS Circular 1306: Science and the Storms - The USGS Response to the Hurricanes of 2005, 50-53.

Rykhus, R. and Lu, Z., 2010. Monitoring a 2003, Yukon flats, Alaska wildfire using multi-temporal Radarsat-1 intensity and interferometric coherence images. IEEE Journal of Selected Topics in Applied Earth Observations (in revision).

Saatchi, S., et al., 2007. Estimation of forest fuel load from radar remote sensing. IEEE Transactions on Geoscience and Remote Sensing, 45 (6), 1726-1740.

Sansosti, E., et al., 1999. Digital elevation model generation using ascending and descending ERS-1/ ERS-2 tandem data. Internatinal Journal of Remote Sensing, 20, 1527-1547.

Schumann, G., et al., 2009. Progress in integration of remote sensing-derived flood extent and stage data and hydraulic models. Review of Geophysics, 47, RG4001.

Serpico, S. and Roli, F., 1995. Classification of multisensory remote-sensing images by structured neural networks. IEEE Transactions on Geoscience, and Remote Sensing, 33, 562-578.

Simard, M., et al., 2006. Mapping height and biomass of Mangrove forests in the Everglades National Park with SRTM dlevation data. Photogrammetric Engineering and Remote Sensing, 72 (3), 299-312.

Simone, G., et al., 2002. Image fusion techniques for remote sensing applications. Information Fusion, 3, 3-15.

Singhroy, V., 1995. SAR integrated techniques for geohazard assessment, natural hazards: monitoring and assessment using remote sensing techniques. Advances in Space Research, 33, 205-290.

Singhroy, V., Matter, K., and Gray, A., 1998. Landslide characterization in Canada using interferometric SAR and combined SAR and TM images. Advances in Space Research, 21, 465-476.

Slatton, K., Crawford, M., and Evan, B., 2001. Fusing interferometric radar and laser altimeter data to estimate surface topography and vegetation heights. IEEE Transactions on Geoscience and Remote Sensing, 39, 2470-2482. 
Solberg, A., Jain, A., and Taxt, T., 1994. Multisource classification of remotely sensed data: fusion of Landsat TM and SAR images. IEEE Transaction on Geoscience and Remote Sensing, 32, $768-778$.

Solberg, A., Taxt, T., and Jain, A., 1996. A Markov random field model for classification of multisource satellite imagery. IEEE Transactions on Geoscience and Remote Sensing, 34, 100-113.

Tholey, N., Clandillon, S., and De Fraipont, P., 1997. The contribution of spaceborne SAR and optical data in monitoring flood events: examples in Northern and Southern France. Hydrological Processes, 11, 1409-1413.

Touzi, R., et al., 2004. A review of polarimetry in the context of synthetic aperture radar: concepts and information extraction. Canadian Journal of Remote Sensing, 30, 380-407.

Townsend, P. and Walsh, S., 1998. Modeling floodplain inundation using an integrated GIS with radar and optical remote sensing. Geomorphology, 21, 295-312.

Townsend, P.A., 2002. Relationships between forest structure and the detection of flood inundation in forest wetlands using C-band SAR. International Journal of Remote Sensing, 23, 443-460.

Tralli, D., et al., 2005. Satellite remote sensing of earthquake, volcano, flood, landslide and coastal inundation hazards. ISPRS Journal of Photogrammetry and Remote Sensing, 59, 185-198.

Tu, T., et al., 2004. A fast intensity-hue-saturation fusion technique with spectral adjustment for IKONOS imagery. IEEE Transactions on Geoscience and Remote Sensing, 42 (4), 309-312.

van Zyl, J., 1989. Unsupervised classification of scattering mechanisms using radar polarimetry data. IEEE Transactions on Geoscience and Remote Sensing, 27, 36-45.

Walker, W., Kellndorfer, J., and Pierce, L., 2007. Quality assessment of SRTM C- and X-band interferometric data: implications for the retrieval of vegetation canopy height. Remote Sensing of Environment, 106, 428-448.

Wang, Y., 2002. Mapping extent of floods: what we have learned and how we can do better. Natural Hazards Review, 3, 68-73.

Wright, T., et al., 2002. Remote monitoring of the earthquake cycle using satellite radar interferometry. Philosophical Transactions of the Royal Society of London, 360, 2873-2888.

Xie, H. and Keller, R., 2006. Fusion of landsat ETM+ and radar data to enhance the extraction of surface and near-subsurface information. Geological Society of America Special Papers, 397, $141-151$.

Yang, X.M., Davis, P., and Dieterich, J., 1988. Deformation from inflation of a dipping finite prolate spheroid in an elastic half-space as a model for volcanic stressing. Journal of Geophysical Research, 93, 4249-4257.

Yocky, D., 1996. Multiresolution wavelet decomposition image merger of Landsat TM and SPOT panchromatic data. Photogrammetric Engineering and Remote Sensing, 62 (3), 295-303.

Zebker, H., et al., 1992. The TOPSAR interferometric radar topographic mapping instrument. IEEE Transactions on Geoscience and Remote Sensing, 30, 933-940.

Zebker, H. and Villasenor, J., 1992. Decorrelation in interferometric radar echoes. IEEE Transactions on Geoscience and Remote Sensing, 30, 950-959.

Zebker, H., Rosen, P., and Hensley, S., 1997. Atmospheric effects in interferometric synthetic aperture radar surface deformation and topographic maps. Journal of Geophysical Research, $102,7547-7563$.

Zebker, H., Shugart, H., and Fahnestock, M. eds., 2007. Report of the July 17-19, 2007 Orlando, Florida, workshop to assess the National Research Council Decadal Survey Recommendation for the DESDynI Radar/Lidar Space Mission.

Zhang, Y., 2009. Adjustable SAR-MS fusion (ASMF) for diverse geo-spatial application. In: Proceedings of joint urban remote sensing conference, Shanghai, China.

Zhang, B., Perrie, W., and He, Y., 2009. Remote sensing of ocean waves by along-track interferometric synthetic aperture radar. Journal of Geophysical Research, 114, C10015. 